\title{
Effect of Low-Frequency rTMS on Electromagnetic Tomography (LORETA) and Regional Brain Metabolism (PET) in Schizophrenia Patients with Auditory Hallucinations
}

\author{
Jiri Horacek ${ }^{a-c}$ Martin Brunovsky ${ }^{\text {a-d }}$ Tomas Novak $^{\text {b, c }}$ Lucie Skrdlantova ${ }^{a}$ \\ Monika Klirova $^{a, b}$ Vera Bubenikova-Valesova ${ }^{b}$ Vladimir Krajca ${ }^{d}$ \\ Barbora Tislerova $^{a} \quad$ Milan Kopecek $^{a-c}$ Filip Spaniel $^{\mathrm{a}-\mathrm{c}}$ Pavel Mohr $^{\mathrm{a}, \mathrm{c}}$ \\ Cyril Höschla-c \\ a Prague Psychiatric Center, ${ }^{b}$ Center of Neuropsychiatric Studies, ${ }^{c} 3 r d$ Medical Faculty of Charles University, and \\ dDepartment of Neurology, Faculty Hospital Bulovka, Prague, Czech Republic
}

\section{Key Words}

Low-frequency rTMS · Schizophrenia • Auditory

hallucinations $\cdot$ Brain metabolism $\cdot$ Lateralization

\begin{abstract}
Background: Auditory hallucinations are characteristic symptoms of schizophrenia with high clinical importance. It was repeatedly reported that low frequency $(\leq 1 \mathrm{~Hz})$ repetitive transcranial magnetic stimulation (rTMS) diminishes treatment-resistant auditory hallucinations. A neuroimaging study elucidating the effect of rTMS in auditory hallucinations has yet to be published. Objective: To evaluate the distribution of neuronal electrical activity and the brain metabolism changes after low-frequency rTMS in patients with auditory hallucinations. Methods: Low-frequency rTMS $(0.9 \mathrm{~Hz}, 100 \%$ of motor threshold, $20 \mathrm{~min})$ applied to the left temporoparietal cortex was used for 10 days in the treatment of medication-resistant auditory hallucinations in schizophrenia $(n=12)$. The effect of rTMS on the low-resolution brain electromagnetic tomography (LORETA) and brain metabolism $\left({ }^{18} \mathrm{FDG}\right.$ PET) was measured before and after 2 weeks of treatment. Results: We found a significant im-
\end{abstract}

provement in the total and positive symptoms (PANSS), and on the hallucination scales (HCS, AHRS). The rTMS decreased the brain metabolism in the left superior temporal gyrus and in interconnected regions, and effected increases in the contralateral cortex and in the frontal lobes. We detected a decrease in current densities (LORETA) for the beta-1 and beta3 bands in the left temporal lobe whereas an increase was found for beta-2 band contralaterally. Conclusion: Our findings implicate that the effect is connected with decreased metabolism in the cortex underlying the rTMS site, while facilitation of metabolism is propagated by transcallosal and intrahemispheric connections. The LORETA indicates that the neuroplastic changes affect the functional laterality and provide the substrate for a metabolic effect.

Copyright $\odot 2007$ S. Karger AG, Basel

\section{Introduction}

Repetitive transcranial magnetic stimulation (rTMS) is a noninvasive method that induces the depolarization of neuron membranes and subsequent functional changes in a discrete area of the cerebral cortex [1]. The effect

\section{KARGER}

Fax +4161306 1234 E-Mail karger@karger.ch www.karger.com
(ㄷ) 2007 S. Karger AG, Basel

0302-282X/07/0554-0132\$23.50/0

Accessible online at:

www.karger.com/nps
Assoc. Prof. Dr. Jiri Horacek, PhD

Prague Psychiatric Center

Ustavni 91

CZ-181 03 Prague 8 (Czech Republic)

Tel. +420 26600 3370, Fax +420 26600 3366, E-Mail horacek@pcp.lf3.cuni.cz 
of rTMS depends on the power of the magnetic field, the localization of the stimuli, and the frequency [2]. Lowfrequency rTMS $(\leq 1 \mathrm{~Hz})$ inhibits the cortical excitability and leads to a weakening of the transfer at the synapses $[3,4]$.

Neuroimaging studies indicate that auditory hallucinations are associated with the overactivity of the auditory-linguistic cortex [5], specifically the left [6] and right $[7,8]$ superior temporal gyri, and Broca's area $[9,10]$. These results are congruent with the finding of abnormal activation of the primary linguistic cortex in hallucinations which competes with auditory stimuli [11]. In the same regions structural abnormalities were also detected [12-13]. The pathology of the auditory-linguistic cortex in auditory hallucinations is a part of a distributed cortical-subcortical network dysfunction [14] which also includes the hippocampal and parahippocampal regions [15].

With respect to the supposed overactivation of the left temporoparietal auditory-linguistic cortex Hoffman et al. [16] published the first report indicating the efficacy of a subthreshold intensity of $1 \mathrm{~Hz}$ rTMS in the treatment of auditory hallucinations in schizophrenia. These promising results were replicated with an extended duration of stimulation for 2 weeks [17] and with a higher intensity of magnetic field [18-21]. Conversely, the effect was not replicated by studies with a treatment period only up to 5 days $[22,23]$ or when the magnetic field was administered in the subthreshold intensity $[24,25]$.

A neuroimaging study elucidating the effect and mechanism of low-frequency rTMS in auditory hallucinations has yet to be published. The general aim of our study was to detect the changes in the intracerebral distribution of neuronal electrical activity and regional brain metabolic changes after a series of low-frequency rTMS treatments in patients with auditory hallucinations.

The effect of rTMS on regional brain metabolism was measured by ${ }^{18}$ fluoro-deoxyglucose $\left({ }^{18} \mathrm{FDG}\right)$ positron emission tomography (PET) in the resting state before and after 2 weeks of rTMS treatment. Because the EEG signals reflect the currents associated with the excitatory and inhibitory postsynaptic potentials [26], a link with brain metabolism (PET) is expected and the information obtained by both methods is expected to be complementary. In contrast to PET, the quantitative EEG has a high temporal resolution (milliseconds), but a spatial resolution limited to the area of the electrode sites. The lowresolution brain electromagnetic tomography (LORETA) represents a new approach to address this problem and permits truly 3-D tomography of electrical brain activity (current density) with no predetermined knowledge about the putative number of discernible source regions [27-29]. We used LORETA to detect the electrophysiological effect on regional functional activity subsequent to the rTMS treatment separately for the different EEG frequency bands with specific functional interpretations.

Due to the expected long-lasting neuroplastic changes induced by the rTMS treatment, we hypothesized that the clinical effect of low-frequency rTMS on hallucinations may be linked to a decrease in glucose metabolism in the left auditory-linguistic cortex (coil position) and corresponding changes in the distribution of cortical neuronal electrical activity with propagation via inter- and intrahemispheric pathways.

\section{Methods}

\section{Subjects}

Our sample consisted of 12 right-handed patients (5 females and 7 males) with a mean age of 34.4 years $(S D=9.1)$ and a mean duration of schizophrenia of 76.3 months $(S D=47.0)$. One additional patient was excluded due to newly diagnosed temporal epilepsy and her case was published separately [30]. All 12 patients met the diagnostic criteria for paranoid schizophrenia according to the DSM-IV. The main inclusion criteria were medication-resistant auditory hallucinations for at least 1 conventional and 1 classical antipsychotic and at least 5 episodes of auditory hallucinations per day during the past month [18]. All patients were on stabile antipsychotic medication for at least 3 weeks before and throughout the rTMS treatment period. Six patients were on monotherapy (olanzapine 15 and $20 \mathrm{mg}$, levomepromazine 50 $\mathrm{mg}$, quetiapine $600 \mathrm{mg}$, amisulpride $900 \mathrm{mg}$, and ziprasidone 160 $\mathrm{mg}$ ), 3 patients were on 2 antipsychotics (risperidone $4 \mathrm{mg}$ with amisulpride $500 \mathrm{mg}$ or clozapine $100 \mathrm{mg}$, and olanzapine $5 \mathrm{mg}$ with haloperidol $4 \mathrm{mg}$ ). The last 3 patients were on a combination with mood stabilizers (lithium carbonicum $1350 \mathrm{mg}$ with sulpiride $500 \mathrm{mg}$ and levomepromazine $25 \mathrm{mg}$, carbamazepine 900 $\mathrm{mg}$ with risperidone $3 \mathrm{mg}$ and ziprasidone $160 \mathrm{mg}$, and carbamazepine $900 \mathrm{mg}$ with quetiapine $800 \mathrm{mg}$ and fluphenazine decanoate $40 \mathrm{mg}$ every 2 weeks).

The standard physical examination, medical history evaluation, biochemistry, ECG and EEG were performed to exclude neurological or medical illness, and drug or alcohol abuse. The investigation was carried out in accordance with the latest version of the Declaration of Helsinki, written informed consent was obtained from all subjects, and the local ethics committee approved the study.

rTMS and the Study Protocol

The psychometric assessments were conducted at baseline (before the first stimulation) and after the 1st and 2nd week of the rTMS treatment. The PET and qEEG were investigated in the resting state within 4 days before and after rTMS treatment. $0.9 \mathrm{~Hz}$ of 
low-frequency rTMS at $100 \%$ of MT was administered over the left temporoparietal region defined as the midway between the $\mathrm{T}_{3}$ and $\mathrm{P}_{3}$ sites according to the international 10/20 EEG electrode system, as described in previous reports [16, 18-21]. In our study, we chose the frequency of $0.9 \mathrm{~Hz}$ instead of $1 \mathrm{~Hz}$ to ensure an inhibitory effect on the brain cortex. The inhibitory effect of $0.9 \mathrm{~Hz}$ rTMS on cortical connectivity or functional coupling has been clearly documented by EEG and a continuous relationship between the frequency and the cortical excitability has been illustrated $[31,32]$. The motor threshold was assessed as the lowest strength of TMS needed to elicit 5 or more electromyographic responses (EMG, Neurosign 400) $\geq 50 \mu \mathrm{V}$ within 10 trials [33]. A Magstim Super Rapid stimulator (Magstim, Whitland, UK) with an air-cooled, figure-eight $70-\mathrm{mm}$ coil was used for $20 \mathrm{~min}$ daily in 10 consecutive working days over 2 weeks with a total number of 10,800 pulses in the study.

\section{Psychometric Measurement}

The clinical effect was assessed by the Positive and Negative Syndrome Scale (PANSS) [34], Hallucination Change Scale (HCS) and the Auditory Hallucination Rating Scale (AHRS). The HCS was scored by requesting the patient to generate a narrative description of the hallucinations and these follow-up scores ranged from 0 to 20 using 10 as the baseline comparison. We used AHRS as an objective composite scale consisting of 7 items (table 1) for a more detailed quantification of the auditory hallucination [18, 20]. The sample was part of a larger study focused on neurobiology and different treatment modalities, the raters were blind to the current treatment.

\section{PET Investigation and Analysis}

The patients were fasted for at least $6 \mathrm{~h}$ before the investigation. In a dimly lit and quiet room, $3 \mathrm{MBq} / \mathrm{kg}$ of ${ }^{18} \mathrm{FDG}$ was administered via a peripheral vein catheter. The patients rested for $30 \mathrm{~min}$ in a specified condition that is described as random episodic silent thinking (REST). The REST produced favorable reliability in PET findings for a schizophrenic population [35]. The data were acquired using the ECAT EXACT 922 (CTI/Siemens, Knoxville, Tenn., USA) PET scanner. The 2-D 'hot' transmission scans were immediately followed by 3-D emission scanning which lasted 15 $\mathrm{min}$. The data were reconstructed by an iterative OS-EM algorithm (matrix: 1,282, brain mode, 47 slices, zoom: 2 , subsets: 16 , iterations: 6, Hann filter: $5 \mathrm{~mm}$ ) and implemented using ECAT 7.2 software. The data analysis was performed using Statistical Parametric Mapping, SPM99 (http://www.fil.ion.ucl.ac.uk/spm) implemented in Matlab (MathWorks, Natick, Mass., USA). The PET scans were normalized into standard stereotactic space and smoothed with an isotropic Gaussian filter (full width at half maximum of $12 \mathrm{~mm}$ ). The global intensity differences were corrected by proportional scaling (global mean to 50 , analysis threshold 0.8 ), and global calculation was performed by the mean voxel value. The paired $t$ test was used to determine the influence of rTMS on the regional brain metabolism. The association between brain metabolism and the severity of auditory hallucinations and clinical improvement was evaluated by the use of total AHRS score and the change of AHRS as the covariates. The $p$ values at a voxel level of $\leq 0.001$ with a minimum of 10 voxels per cluster (extent threshold) were considered statistically significant for the regions involved in the a priori hypothesis (the left auditory-linguistic cortex and directly interconnected regions). We tested the connectivity between the left superior temporal gyrus underlying the focus of the rTMS coil and the entire brain. We extracted the mean metabolism for the left superior temporal gyrus using VoiTool software (http://www.ihb.spb.ru/ pet_lab/VTO) and these measures were used as the covariate before and after the rTMS.

\section{EEG Investigation and LORETA Analysis}

The EEG data for the LORETA analysis were analyzed in a subgroup of 9 patients ( 5 males and 4 females, mean age $=32.4$, $\mathrm{SD}=7.4$, mean schizophrenia duration $=104.3$ months, $\mathrm{SD}=$ 52.7). The EEG data from the remaining 3 patients were not analyzed due to the inability of the patients to perform either one of the two EEG examinations. Studies were performed using the BrainScope amplifier system (Unimedis, Prague, Czech Republic) with 19 electrodes placed according to the International 10-20 system. Subjects were resting in an alert state with their eyes closed in a sound-attenuated room with subdued lighting. During the recording, the alertness was controlled. If the patterns of drowsiness appeared in the EEG, the subjects were aroused by acoustic stimuli. All signals were sampled with a frequency of 250 $\mathrm{Hz}$ and a $0.5-$ to $70-\mathrm{Hz}$ filter. Before analysis, artifact detection was performed visually with the exclusion of all EEG segments that contained obvious eye and head movements, muscle artifacts or a decrease in alertness. After recomputation to the average reference, spectral analysis was performed for at least six artifactfree 5-second epochs with the data digitally filtered according to Kubicki et al. [36] into 7 frequency bands: delta $(1.5-6 \mathrm{~Hz})$, theta (6.5-8 Hz), alpha-1 (8.5-10 Hz), alpha-2 (10.5-12 Hz), beta-1 $(12.5-18 \mathrm{~Hz})$, beta-2 $(18.5-21 \mathrm{~Hz})$ and beta-3 $(21.5-30 \mathrm{~Hz})$. Subsequently, the $3-\mathrm{D}$, intracerebral current density distribution was estimated by LORETA [27-29, 37]. Localization of the differences in electrical activity was assessed by voxel-by-voxel paired t tests of the LORETA images, based on the log-transformed power of the estimated electric current density. To visualize the global distributions of the voxel-by-voxel paired t test differences, we computed the mean center of gravity location of all voxels with positive and negative $t$ values for each band. To correct for multiple comparisons, a nonparametric single-threshold test was applied on the basis of the theory for randomization and permutation tests [38]. The omnibus null hypothesis of no activation anywhere in the brain was rejected if at least one $t$ value (i.e. voxel, $t_{\max }$ ) was above the critical threshold $\left(\mathrm{t}_{\text {crit }}\right)$ for $\mathrm{p}=0.05$, determined by 5,000 randomizations.

\section{Statistical Analyses}

We used the mean and standard deviation for descriptive statistics. Due to non-normally distributed variables in the psychometric scales (Shapiro-Wilk test $\mathrm{p} \leq 0.05$ ), the results and percentage change from the baseline are reported as medians with an interquartile range. Friedman's test with the Wilcoxon signed rank post-hoc test and a Bonferroni correction for multiple comparisons were performed in the analysis of hallucination ratings and PANSS. A p value of less than 0.05 for the Friedman and Wilcoxon signed rank tests was regarded as significant and the criterion alpha (two-tailed) after a Bonferroni correction for multiple comparisons was set at 0.016 . We performed all statistical computations with Statsoft Statistica 7.0. 
Table 1. Clinical effect of rTMS on auditory hallucinations in schizophrenia $(\mathrm{n}=12)$ assessed by HCS, AHRS (total and individual items), positive, negative symptoms and the total PANSS score

\begin{tabular}{lccc}
\hline & Baseline & After 1 week & After 2 weeks \\
\hline Positive PANSS & $17.5(14.5-20.0)$ & $14.5(13.0-18.0)^{*}$ & $14.0(13.0-16.0)^{*}$ \\
PANSS P-3 & $4.5(4.0-5.0)$ & $4.0(3.0-4.5)$ & $3.0(3.0-4.0)^{*}$ \\
Negative PANSS & $20.0(16.0-23.5)$ & $20.0(16.5-22.5)$ & $20.0(16.5-21)$ \\
Total PANSS & $70.0(60.5-85.0)$ & $70.5(58.5-77.5)$ & $66.0(58.0-70.0)^{*}$ \\
HCS & $10(10-10)$ & $7.5(6.5-9.0)^{*}$ & $7.5(4.5-9.5)^{*}$ \\
Total AHRS & $25.0(23.0-32.0)$ & $21.0(19.5-24.5)^{*}$ & $17.0(14.0-23.0)^{*}$ \\
AHRS & & & \\
$\quad$ Frequency & $4.0(2.0-6.5)$ & $3.5(2.5-4.0)$ & $2.5(1.0-4.0)$ \\
$\quad$ Reality & $4.0(4.0-5.0)$ & $4.0(4.0-4.0)$ & $3.5(1.5-4.0)$ \\
$\quad$ Loudness & $3.0(3.0-4.0)$ & $2.0(2.0-3.0)^{*}$ & $2.5(1.5-3.0)$ \\
$\quad$ Number of voices & $2.0(1.0-3.5)$ & $1.5(1.0-2.0)$ & $2.0(1.0-2.5)$ \\
$\quad$ Length & $3.0(3.0-4.0)$ & $3.0(2.5-3.5)$ & $2.5(1.5-3.0)$ \\
$\quad$ Attentional salience & $5.0(4.5-5.0)$ & $4.0(3.0-4.5)$ & $3.0(2.0-4.5)^{*}$ \\
$\quad$ Distress level & $4.0(3.5-5.0)$ & $3.0(3.0-4.0)^{*}$ & $2.5(1.5-3.5)^{*}$ \\
\hline
\end{tabular}

Data are presented in medians (interquartile range). The differences between the baseline and values after 1 and 2 weeks of rTMS were determined by the Friedman test followed by the post-hoc Wilcoxon paired test. The $p$ values are $\leq 0.05$ with a Bonferroni correction for the 2 time points (marked by an asterisk).

\section{Results}

\section{Clinical Effect of rTMS}

With the exception of mild headaches, the rTMS treatment was well tolerated. The effect of rTMS on the psychometric measurements is presented in table 1. After 2 weeks of treatment, we found a significant decrease in the Hallucination item as well as in the positive and total PANSS score. We did not find an effect on the negative or the global PANSS subscale. We detected significant decreases in both the total AHRS and HCS after the 1st and 2nd week of treatment. The analysis for the separate AHRS items showed a significant effect on the loudness of voices and distress levels after the 1st week. At the end of the rTMS treatment, the effect on distress levels was more pronounced and a significant decrease was found for attentional salience ( $\mathrm{p} \leq 0.05)$.

\section{Effect of rTMS on Brain Metabolism (PET)}

Decreases in regional brain metabolism after 2 weeks of rTMS treatment were found in the regions corresponding to the coil position, such as the left superior and inferior temporal gyri and insula (table 2). The metabolism also decreased in the left cerebellum, cuneus and bilaterally in the hippocampus (fig. 1a). The ${ }^{18} \mathrm{FDG}$ uptake increased (fig. 1b) bilaterally in the middle frontal gyrus and contralaterally to the site of stimulation in the temporal and occipital cortex $(\mathrm{t}=4.02, \mathrm{p} \leq 0.001)$.

rTMS, LORETA and PET in

Hallucinations
Due to the lateralized metabolic effect, we supposed that the series of rTMS affects the functional connectivity of left superior temporal gyrus. To evaluate this hypothesis we used the mean ${ }^{18}$ FDG uptake in the left superior temporal gyrus as a covariate of the entire brain volume metabolism. Before rTMS, we found a robust positive covariation with a large cluster consisting of the bilateral, lateral and medial temporal cortices. After rTMS, the positive covariation generally decreased and remained significant for the left temporal cortex in particular. In addition, the negative covariation decreased after rTMS for the pre- and postcentral gyri and parietal regions. However, the new negative covariation was detected for the right superior frontal gyrus. For exact locations and coordinates, see figure 2 .

To identify the association between regional brain metabolism and the severity of auditory hallucinations, we used the AHRS score as the covariate. Before rTMS treatment, the total AHRS score positively correlated with regional brain metabolism in the left interior temporal gyrus (54 voxels) and to a lesser extent in the right middle frontal gyrus (13 voxels). After treatment, the AHRS score positively correlated with the right middle temporal gyrus (145 voxels). To detect the association between the pretreatment regional brain metabolism and clinical effect of rTMS, we used the change of AHRS during the study as the covariate for the ${ }^{18}$ FDG uptake before treatment. The AHRS change was positively predicted by the

Neuropsychobiology 2007;55:132-142 
Fig. 1. The influence of low frequency rTMS on regional brain metabolism. a The most pronounced decrease in ${ }^{18}$ FDG PET uptake was found in the left temporal cortex and in the cerebellum. b ${ }^{18}$ FDG PET uptake following low-frequency rTMS increased in the middle frontal gyrus bilaterally and in the right temporoparietal cortex. For a list of all significant changes and technical details, see table 2 . $\mathrm{R}=$ Right hemisphere; $\mathrm{L}=$ left hemisphere.

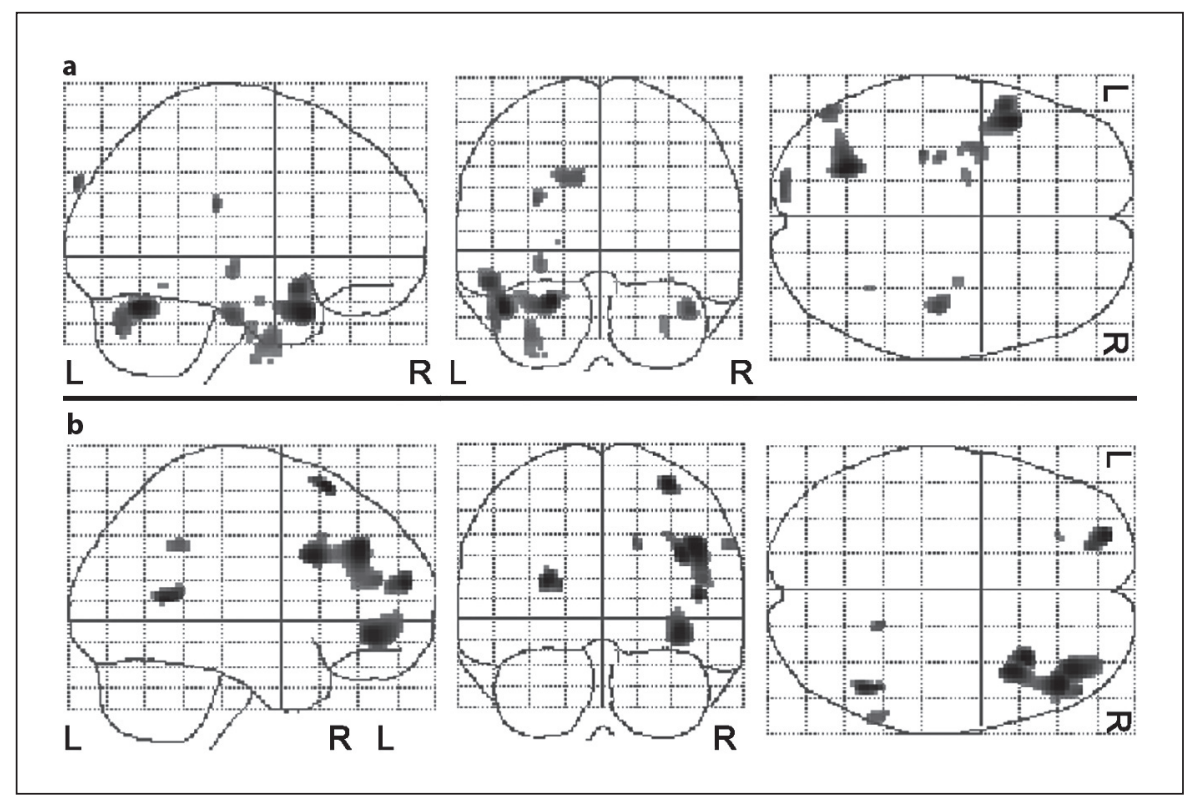

Table 2. Comparison of ${ }^{18}$ FDG uptake PET measured before and after $0.9-\mathrm{Hz}$ rTMS treatment

\begin{tabular}{|c|c|c|c|c|c|c|}
\hline $\begin{array}{l}\text { Cluster } \\
\text { size }\end{array}$ & $\mathrm{x}$ & $\mathrm{y}$ & $\mathrm{z}$ & $\begin{array}{l}\text { Hemi- } \\
\text { sphere }\end{array}$ & Brain region & $\mathrm{BA}$ \\
\hline \multicolumn{7}{|c|}{ Decrease in ${ }^{18} \mathrm{FDG}$ uptake after rTMS } \\
\hline 252 & -46 & 14 & -26 & $\mathrm{~L}$ & superior temporal gyrus & 38 \\
\hline- & -52 & 12 & -16 & $\mathrm{~L}$ & superior temporal gyrus & 38 \\
\hline 167 & -22 & -64 & -24 & $\mathrm{~L}$ & cerebellum-hemisphere, lobule 6 & \\
\hline 56 & 42 & -20 & -28 & $\mathrm{R}$ & inferior temporal gyrus & 20 \\
\hline 54 & -50 & -72 & -32 & $\mathrm{~L}$ & cerebellum-hemisphere, lobule crus2 & \\
\hline 11 & -30 & -28 & 24 & $\mathrm{~L}$ & insula & 13 \\
\hline 33 & -12 & -94 & 34 & $\mathrm{~L}$ & cuneus & 19 \\
\hline 78 & -32 & -2 & -40 & $\mathrm{~L}$ & inferior temporal gyrus & 20 \\
\hline - & -32 & -10 & -50 & $\mathrm{~L}$ & inferior temporal gyrus & 20 \\
\hline 19 & -28 & -20 & -6 & $\mathrm{~L}$ & hippocampus & \\
\hline 15 & 30 & -10 & -34 & $\mathrm{R}$ & uncus & 20 \\
\hline \multicolumn{7}{|c|}{ Increase in ${ }^{18} \mathrm{FDG}$ uptake after rTMS } \\
\hline 35 & 32 & 20 & 64 & $\mathrm{R}$ & middle frontal gyrus & 9 \\
\hline 382 & 44 & 36 & 34 & $\mathrm{R}$ & middle frontal gyrus & 9 \\
\hline- & 38 & 16 & 30 & $\mathrm{R}$ & middle frontal gyrus & 9 \\
\hline - & 48 & 44 & 20 & $\mathrm{R}$ & middle frontal gyrus & 46 \\
\hline 79 & -26 & 58 & 18 & $\mathrm{~L}$ & middle frontal gyrus & 10 \\
\hline 237 & 38 & 42 & -6 & $\mathrm{R}$ & middle frontal gyrus & 47 \\
\hline 36 & 46 & -54 & 10 & $\mathrm{R}$ & superior temporal gyrus & 39 \\
\hline 10 & 16 & -48 & 36 & $\mathrm{R}$ & precuneus & 31 \\
\hline 19 & 60 & -50 & 36 & $\mathrm{R}$ & supramarginal gyrus & 40 \\
\hline
\end{tabular}

The cluster size is presented as the number of voxels over the statistical threshold $\mathrm{t}=4.02$ corresponding to a $\mathrm{p}$ value of 0.001 . Dashes in the cluster size column indicate that the peak belongs to the same cluster as above. $\mathrm{R}=$ Right hemisphere; $\mathrm{L}=$ left hemisphere; $x y z=$ coordinates of the MNI space for each maximum; $B A=$ Brodmann area. 


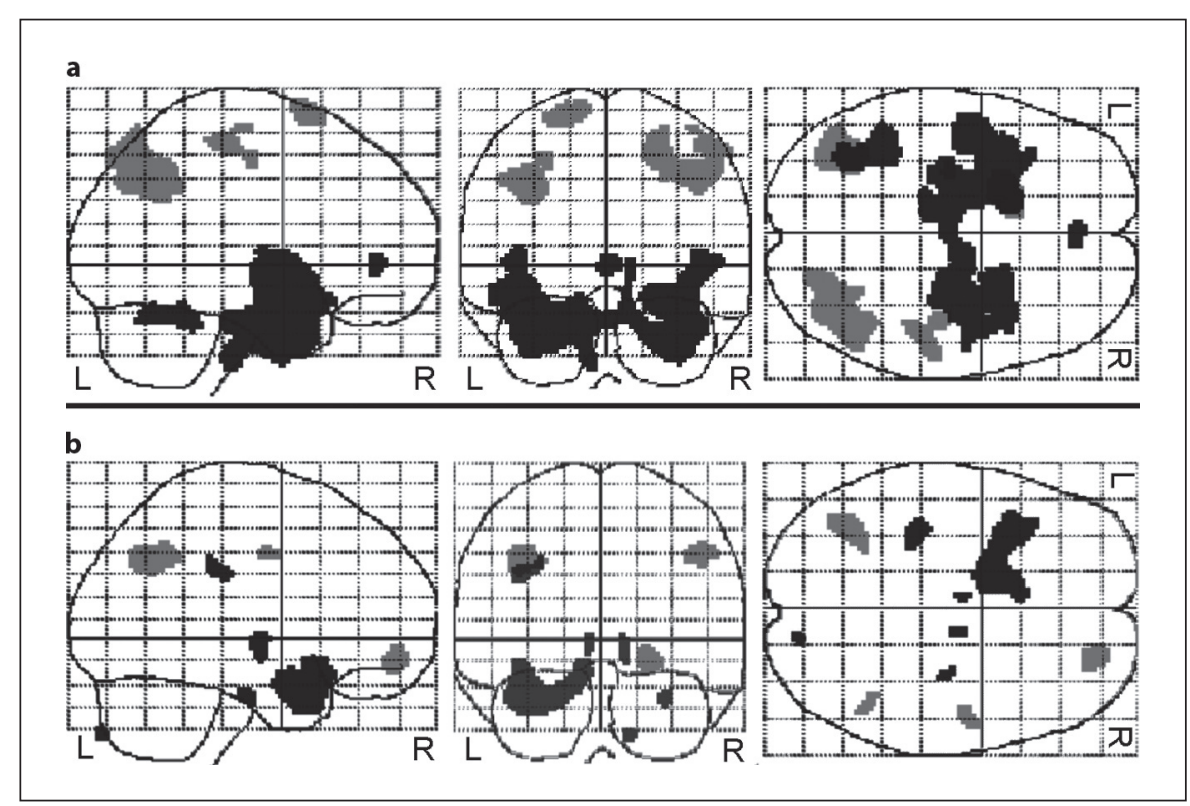

Fig. 2. Positive (black) and negative (gray) covariation between the mean ${ }^{18} \mathrm{FDG}$ uptake in the left superior temporal cortex and the whole brain before (a) and after (b) rTMS treatment. Before rTMS, we found a positive covariation with the large cluster consisting of the bilateral inferior, middle and superior temporal gyri, parahippocampal gyrus, uncus and insula, with the bilateral anterior cingulate and left fusiform gyrus. After rTMS, the positive covariation remained significant for the left superior temporal gyrus, uncus, postcentral gyrus, right uncus and cerebellum, and bilaterally for the subthalamic nucleus. The negative covariation before rTMS was detected with the inferior parietal lobule, precuneus, postcentral and precentral gyri on the right side, and with left precentral gyrus, superior frontal gyrus and precuneus. After rTMS, the negative covariation was detected only in the right precentral and superior frontal gyri, right inferior parietal lobule and left precuneus ( $\mathrm{p} \leq 0.001)$. pretreatment metabolism in the left inferior temporal gyrus (34 voxels) and parahippocampal gyrus (13 voxels) and the right precentral gyrus (478 voxels). The higher metabolism in the left inferior frontal gyrus (16 voxels) was the negative predictor of clinical improvement $(\mathrm{t}=$ $4.14, \mathrm{p} \leq 0.001$ for all covariation analyses).

\section{Effect of rTMS on LORETA}

For a list of all significant changes and the coordinates for each maximum, see figure 3 . In the anterior cingulate, we found a bilateral increase in current densities in the delta band (fig. 3a). The current densities decreased in the beta- 1 and beta- 3 bands in the temporal lobe ipsilateral to the site of stimulation (fig. $3 \mathrm{~b}, \mathrm{~d}$ ). In the beta- 2 band (fig. 3c), we found an increase in the current densities in the middle temporal and in the inferior parietal lobule on the right side. The significant changes were not detected for the theta, alpha-1, and alpha-2 bands.

\section{Discussion}

Our data confirm that low-frequency rTMS is effective in the treatment of auditory hallucinations [16-21]. With respect to the previous studies with negative results [2225] our results are in favor of rTMS application of a longer duration (20 min per day for 10 days) with a higher intensity of magnetic field up to $100 \% \mathrm{MT}$. The similar trend for rTMS therapeutic efficacy in relation to the higher number of pulses and magnetic field intensity is documented for depression [39]. However, our study was focused on the detection of neuroimaging changes and hence this clinical presumption may be confirmed by a sham-controlled study.

The decrease in brain metabolism in the temporal cortical region ipsilateral to the coil position is congruent with the inhibitory effect of the low-frequency rTMS [40, 41] and with the a priori formulated hypothesis. Resting ${ }^{18}$ FDG PET primarily reflects the regional glutamate turnover at the synaptic (particularly, presynaptic) level 
Fig. 3. The effect of rTMS on the current densities measured by LORETA. a The signal after the rTMS exhibited an increase in the delta band of the anterior cingulate bilaterally (xyz $=-3,-11,-6$; BA 25). b In the beta- 1 band, the decrease in current densities was detected in the left superior temporal gyrus (xyz $=-52,-25,8$; BA 41) and left fusiform gyrus (xyz $=-59,-32,-27$, BA 20). d The similar decrease in current densities ipsilateral to the site of stimulation was also detected for beta- 3 in the middle $(\mathrm{xyz}=-66,-25,-6$; BA 21) and superior $(\mathrm{xyz}=-66,-25,1$; BA 22) temporal gyri. c In the beta- 2 band we found an increase in the current densities in the middle temporal gyrus $(x y z=46,-39,1$; BA 22$)$ and in the inferior parietal lobule $(x y z=39$, $-32,43$; BA 40 ) on the right side. The paired $t$ test was used with corrected $p$ values $\leq 0.05$. xyz signify coordinates of the Talairach space for each maximum.

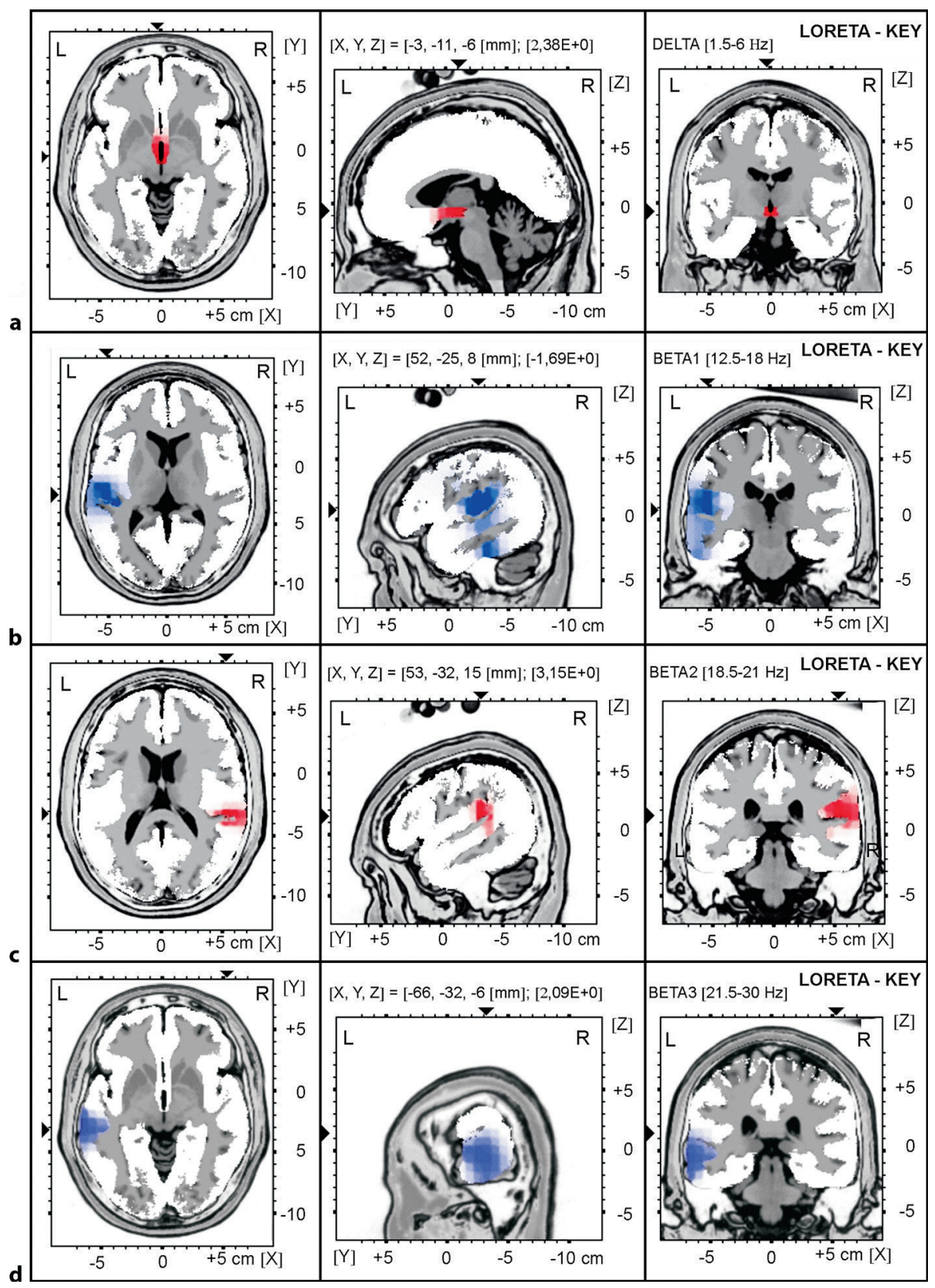

and provides a probe for relative synaptic strength and consequent metabolic activity $[42,43]$. Therefore, our observation is in accordance with the supposed long-term depression phenomenon induced by low-frequency rTMS as the most probable mechanism responsible for the inhibitory effect $[3,4]$. Considering the focus of the coil position estimated to be over the posterior part of the superior temporal gyrus, the anatomical location of the prominent decrease in ${ }^{18} \mathrm{FDG}$ uptake was shifted rostrally (anterior part of the superior temporal gyrus) and me- dially (insula). A similar effect of anteriomedially shifted metabolic decrease in relation to the coil position was detected for low-frequency rTMS over the left prefrontal cortex [41]. This mild shift in the inhibitory changes may result from the induced spread of the physiologic effect in the temporal cortex to the lower stages of auditory information processing in the anterior part [44]. The decreased metabolism in this region is congruent with the clinical effect that is most pronounced in the loudness and attentional salience of AHRS and less so on the more complex 
features, such as the reality or number of voice items. The covariation analyses confirmed that the overmetabolism in left temporal cortex correlates with the pretreatment intensity of hallucinations and represents the positive predictor of the clinical effect of rTMS.

We also found the metabolic decrease in cerebellum and hippocampus. The decrease in metabolism in the hippocampus could be mediated through well-established connections from both the temporal [45] and prefrontal cortices [46, 47]. Cerebellum is not directly interconnected with the temporoparietal region of coil positioning and so it was not involved in the a priori hypothesis on metabolic changes under the coil and directly interconnected regions. Hence, in the case of cerebellum the PET results presented at $\mathrm{p} \leq 0.001$ without correction for multiple comparisons should be interpreted cautiously considering the risk of false-positive results. Nevertheless, tracer studies in primates have confirmed that the cerebellum is interconnected with areas 9 and 46 of the prefrontal cortex $[48,49]$. Thus the changes induced by rTMS in the prefrontal region might be responsible for the indirect modulatory effect in the cerebellum.

The increased metabolism in the bilateral middle frontal gyrus is analogous to findings from the low-frequency prefrontal rTMS study by Speer et al. [40] that proved decreased prefrontal perfusion with simultaneous intensity-dependent increases in distant interconnected areas. The authors explained these phenomena by the projections from the site of stimulation to the inhibitory interneurons. The primary changes induced by rTMS in the temporal cortex may cause a marked metabolic increase in the prefrontal cortex (and vice versa) via long intrahemispheric fascicules that highly interconnect both parts. The facilitation of metabolism in the frontal lobes implicates that low-frequency rTMS in the temporal location may improve the symptoms derived from the hypofrontality and induce the reintegration of frontotemporal disconnection documented in schizophrenia [50, 51].

The surprising finding is the increase in ${ }^{18} \mathrm{FDG}$ uptake in the right temporoparietal cortex. The decrease in metabolism in the left temporal cortex may cause a marked metabolic compensatory-like increase in the right corresponding cortex. The similar contralateral effect with the opposite direction was observed also in high-frequency rTMS $[52,53]$. The differences in the beta band density distribution found in our study by LORETA were in accordance with a lateralized metabolic effect obtained by PET analysis. The conventional separation of the beta rhythm into beta-1, beta-2, and beta- 3 bands is based on factor analysis [36] but the physiological relevance is still not yet explained. Generally, the beta represents the excitatory frequency but in vitro experiments indicate that the increase in beta may be observed both in the increased excitatory activity as well as during induced $\mathrm{GABA}_{\mathrm{A}}$ receptor activation [54]. In our experiment, the decrease in current density in beta- 1 and beta- 3 frequency bands in the temporal lobe ipsilateral to the site of stimulation and the increase in beta-2 band in the temporoparietal cortex on the contralateral side correspond with the PET findings. These lateralized changes in the metabolism and beta oscillations are in agreement with the recent PET and LORETA study, in which the beta- 1 and beta- 3 activities correlated positively but the beta- 2 negatively with the brain metabolism [55]. Our data indicate that the rTMS affects the populations of excitatory pyramidal cells and interneurons differently under the coil position and in the transcallosal projection area. In contrast to our findings, the recent study by Jandl et al. [21] did not detect any significant changes in the spectral EEG analysis of hallucinating patients treated by rTMS. However, this study was limited by the duration of the treatment period (5 days) and particularly by the chosen method of quantitative EEG.

The communication between spatially separate sites is predominantly mediated by pyramidal neurons via their long axons which in the projecting area synchronize both inhibitory interneurons and excitatory neurons [56]. We hypothesize that the rTMS-induced inhibition of the left temporal cortex resulted in lower inputs to the contralateral areas, as documented by the decrease in positive covariation between ${ }^{18} \mathrm{FDG}$ uptake in the left superior temporal gyrus and the corresponding contralateral regions (fig. 2). This proposed mechanism may be a long-lasting analogue to the recently documented interhemispheric compensation (and competition) in information processing after an acute rTMS-induced virtual lesion [57]. The LORETA findings in the beta- 2 band could contribute to the elucidation of the phenomena. The analysis between the $\mathrm{GABA}_{\mathrm{A}}$ receptor gene locus and the beta frequency spectrum indicated that the beta2 band has the highest linkage to $\mathrm{GABA}_{\mathrm{A}}$ receptors compared to beta- 1 and beta-3 [58]. Therefore, we speculate that the increase in beta- 2 current density and metabolism contralateral to the site of stimulation may be caused by the decreased GABA neuron activity subsequent to the lower transcallosal inputs and following recurrent excitation [59]. 
The increase in current density in the delta band in the anterior cingulate indicates an increase in inhibitory processes in this region $[60,61]$ subsequent to the rTMS. The overactivity in this region was previously detected in positive schizophrenia symptoms $[62,63]$ and the increase in delta may reflect their improvement. These changes in the cingulate may result from indirect stimulation of the prefrontal cortex which has dense inhibitory connections to cingulate [64]. The lack of corresponding findings in the cingulate in our PET data is explained by the higher temporal sensitivity in EEG which enables the detection of the increased inhibitory oscillation in the delta band. The low correlation of the delta band with PET and the higher correlation for the beta frequency increase were documented in a concurrent FDG PET and LORETA neuroimaging study [55].

It is necessary to emphasize that the metabolic and EEG effect in our study was induced by long-term stimulation applied over 2 weeks. The ${ }^{18} \mathrm{FDG}$ uptake in resting condition directly correlates with the synaptophysin level and should be accepted as the marker of synaptic density [43]. The EEG spectral distribution is stable over time in individual subjects $[65,66]$ and exerts heritability for all bands with the highest heritability for beta [67]. Therefore, in contrast to previous studies focused on acute perfusion or excitability changes $[68,69]$ the differences in both methods during rTMS treatment confirm the longlasting neuroplastic remodeling of synaptic architecture and cortical integration in our experiment.

\section{Conclusion}

Our findings confirm the effect of rTMS on auditory hallucinations, and a decreased metabolism in the cortex underlying the rTMS site. We detected the metabolic influence propagated by transcallosal and intrahemispheric connections. The LORETA analysis corresponds to the PET data in the beta bands and indicates that the neuroplastic changes serve as the substrate for the metabolic effect.

\section{Acknowledgments}

This research was supported by grants NR8792 and 1A8600-4 from the Grant Agency of the Ministry of Health, the Czech Republic, grant 1ET101210512 from the Grant Agency of the Academy of Science, the Czech Republic, and by projects $1 \mathrm{M} 0517$ and VZ 0021620816 from the Ministry of Education, Youth and Sports, the Czech Republic. The authors thank Craig Hampson for linguistic assistance.

\section{References}

1 Barker AT, Jalinous R, Freeston IL: Non-invasive magnetic stimulation of human motor cortex. Lancet 1985; i:1106-1107.

2 George MS, Nahas Z, Kozel FA, LiX, Denslow S, Yamanaka K, Mishory A, Foust MJ, Bohning DE: Mechanisms and state of the art of transcranial magnetic stimulation. J ECT 2002;18:170-181.

>3 Chen R, Classen J, Gerloff C, Celnik P, Wassermann EM, Hallett M, Cohen LG: Depression of motor cortex excitability by low-frequency transcranial magnetic stimulation. Neurology 1997;48:1398-1403.

4 Pascual-Leone A, Tarazona F, Keenan J, Tormos JM, Hamilton R, Catala MD: Transcranial magnetic stimulation and neuroplasticity. Neuropsychologia 1999;37:207-217.

5 Copolov DL, Seal ML, Maruff P, Ulusoy R, Wong MT, Tochon-Danguy HJ, Egan GF: Cortical activation associated with the experience of auditory hallucinations and perception of human speech in schizophrenia: a PET correlation study. Psychiatry Res 2003; 122:139-152.
6 Suzuki M, Yuasa S, Minabe Y, Murata M, Kurachi M: Left superior temporal blood flow increases in schizophrenic and schizophreniform patients with auditory hallucination: a longitudinal case study using 123IIMP SPECT. Eur Arch Psychiatry Clin Neurosci 1993;242:257-261.

7 Shergill SS, Brammer MJ, Williams SC, Murray RM, McGuire PK: Mapping auditory hallucinations in schizophrenia using functional magnetic resonance imaging. Arch Gen Psychiatry 2000;57:1033-1038.

$\checkmark 8$ Volkow ND, Wolf AP, Van Gelder P, Brodie JD, Overall JE, Cancro R, Gomez-Mont F: Phenomenological correlates of metabolic activity in 18 patients with chronic schizophrenia. Am J Psychiatry 1987;144:151-158.

9 McGuire PK, Shah GM, Murray RM: Increased blood flow in Broca's area during auditory hallucinations in schizophrenia. Lancet 1993;342:703-706.

-10 Cleghorn JM, Garnett ES, Nahmias C, Brown GM, Kaplan RD, Szechtman H, Szechtman B, Franco S, Dermer SW, Cook P: Regional brain metabolism during auditory hallucinations in chronic schizophrenia. Br J Psychiatry 1990;157:562-570.
11 Hubl D, Koenig T, Strik WK, Garcia LM, Dierks T: Competition for neuronal resources: how hallucinations make themselves heard. Br J Psychiatry 2007;190:57-62.

12 Menon RR, Barta PE, Aylward EH, Richards SS, Vaughn DD, Tien AY, Harris GJ, Pearlson GD: Posterior superior temporal gyrus in schizophrenia: grey matter changes and clinical correlates. Schizophr Res 1995;16: 127-135.

$\checkmark 13$ Kim JJ, Crespo-Facorro B, Andreasen NC, O'Leary DS, Magnotta V, Nopoulos P: Morphology of the lateral superior temporal gyrus in neuroleptic naive patients with schizophrenia: relationship to symptoms. Schizophr Res 2003;60:173-181.

14 Silbersweig D, Stern E: Functional neuroimaging of hallucinations in schizophrenia: toward an integration of bottom-up and topdown approaches. Mol Psychiatry 1996;1: 367-375. 
15 Musalek M, Podreka I, Suess E, Nutzinger D, Passweg V, Strobl R, Walter H, Baumgartner C, Lesch OM: Neurophysiological aspects of auditory hallucinations. 99mTc-(HMPAO)SPECT investigations in patients with auditory hallucinations and normal controls - a preliminary report. Psychopathology 1988; 21:275-280.

-16 Hoffman RE, Boutros NN, Hu S, Berman RM, Krystal JH, Charney DS: Transcranial magnetic stimulation and auditory hallucinations in schizophrenia. Lancet 2000;355: 1073-1075.

$\checkmark 17$ d'Alfonso AA, Aleman A, Kessels RP, Schouten EA, Postma A, van Der Linden JA, Cahn W, Greene Y, de Haan EH, Kahn RS: Transcranial magnetic stimulation of left auditory cortex in patients with schizophrenia: effects on hallucinations and neurocognition. J Neuropsychiatry Clin Neurosci 2002;14:77-79.

18 Hoffman RE, Hawkins KA, Gueorguieva R, Boutros NN, Rachid F, Carroll K, Krystal JH: Transcranial magnetic stimulation of left temporoparietal cortex and medication-resistant auditory hallucinations. Arch Gen Psychiatry 2003;60:49-56.

19 Lee SH, Kim W, Chung YC, Jung KH, Bahk WM, Jun TY, Kim KS, George MS, Chae JH: A double blind study showing that two weeks of daily repetitive TMS over the left or right temporoparietal cortex reduces symptoms in patients with schizophrenia who are having treatment-refractory auditory hallucinations. Neurosci Lett 2005;376:177-181.

-20 Hoffman RE, Gueorguieva R, Hawkins KA, Varanko M, Boutros NN, Wu YT, Carroll K, Krystal JH: Temporoparietal transcranial magnetic stimulation for auditory hallucinations: safety, efficacy and moderators in a fifty patient sample. Biol Psychiatry 2005;58: 97-104.

-21 Jandl M, Steyer J, Weber M, Linden DE, Rothmeier J, Maurer K, Kaschka WP: Treating auditory hallucinations by transcranial magnetic stimulation: a randomized controlled cross-over trial. Neuropsychobiology 2006;53:63-69.

-22 McIntosh AM, Semple D, Tasker K, Harrison LK, Owens DG, Johnstone EC, Ebmeier KP: Transcranial magnetic stimulation for auditory hallucinations in schizophrenia. Psychiatry Res 2004;127:9-17.

-23 Schonfeldt-Lecuona C, Gron G, Walter H, Buchler N, Wunderlich A, Spitzer M, Herwig $\mathrm{U}$ : Stereotaxic rTMS for the treatment of auditory hallucinations in schizophrenia. Neuroreport 2004;15:1669-1673.

-24 Saba G, Verdon CM, Kalalou K, Rocamora JF, Dumortier G, Benadhira R, Stamatiadis L, Vicaut E, Lipski H, Januel D: Transcranial magnetic stimulation in the treatment of schizophrenic symptoms: a double blind sham controlled study. J Psychiatr Res 2006; 40:147-152.
25 Fitzgerald PB, Benitez J, Daskalakis JZ, Brown TL, Marston NA, de Castella A, Kulkarni J: A double-blind sham-controlled trial of repetitive transcranial magnetic stimulation in the treatment of refractory auditory hallucinations. J Clin Psychopharmacol 2005;25:358-362.

26 Nunez PL, Silberstein RB: On the relationship of synaptic activity to macroscopic measurements: does co-registration of EEG with fMRI make sense? Brain Topogr 2000;13: 79-96.

-27 Pascual-Marqui RD, Michel CM, Lehmann D: Low resolution electromagnetic tomography: a new method for localizing electrical activity in the brain. Int J Psychophysiol 1994;18:49-65.

28 Pascual-Marqui RD, Esslen M, Kochi K, Lehmann D: Functional imaging with lowresolution brain electromagnetic tomography (LORETA): a review. Methods Find Exp Clin Pharmacol 2002;24(suppl C):91-95.

29 Pascual-Marqui RD, Lehmann D, Koenig T: Low resolution brain electromagnetic tomography (LORETA) functional imaging in acute, neuroleptic-naive, first-episode, productive schizophrenia. Psychiatry Res 1999; 90:169-179.

30 Horacek J, Brunovsky M, Kopecek M: Chronicke akusticke verbalni halucinace pri temporalni epilepsii. Kazuisticka studie EEG, qEEG a 18FDG PET. Psychiatrie 2004; 8:225-230.

31 Maeda F, Keenan JP, Tormos JM, Topka H, Pascual-Leone A: Interindividual variability of the modulatory effects of repetitive transcranial magnetic stimulation on corti cal excitability. Exp Brain Res 2000;133: 425-430.

32 Chen WH, Mima T, Siebner HR, Oga T, Hara $\mathrm{H}$, Satow T, Begum T, Nagamine T, Shibasaki H: Low-frequency rTMS over lateral premotor cortex induces lasting changes in regional activation and functional coupling of cortical motor areas. Clin Neurophysiol 2003;114:1628-1637.

33 Rossini PM, Barker AT, Berardelli A, Caramia MD, Caruso G, Cracco RQ, Dimitrijevic MR, Hallett M, Katayama Y, Lucking $\mathrm{CH}$, et al: Non-invasive electrical and magnetic stimulation of the brain, spinal cord and roots: basic principles and procedures for routine clinical application. Report of an IFCN committee. Electroencephalogr Clin Neurophysiol 1994;91:79-92.

34 Kay SR, Fiszbein A, Opler LA: The positive and negative syndrome scale (PANSS) for schizophrenia. Schizophr Bull 1987;13:261276.

35 Andreasen NC, O'Leary DS, Cizadlo T, Arndt S, Rezai K, Watkins GL, Ponto LL, Hichwa RD: Remembering the past: two facets of episodic memory explored with positron emission tomography. Am J Psychiatry 1995;152:1576-1585.
36 Kubicki S, Herrmann WM, Fichte K, Freund G: Reflections on the topics: EEG frequency bands and regulation of vigilance. Pharmakopsychiatr Neuropsychopharmakol 1979; 12:237-245.

37 Pascual-Marqui RD: Review of methods for solving the EEG inverse problem. Int J Bioelectromagnet 1999;1:75-86.

38 Holmes AP, Blair RC, Watson JD, Ford I: Nonparametric analysis of statistic images from functional mapping experiments. J Cereb Blood Flow Metab 1996;16:7-22.

39 Fitzgerald PB, Brown TL, Daskalakis ZJ: The application of transcranial magnetic stimulation in psychiatry and neurosciences research. Acta Psychiatr Scand 2002;105:324340.

40 Speer AM, Willis MW, Herscovitch P, DaubeWitherspoon M, Shelton JR, Benson BE, Post RM, Wassermann EM: Intensity-dependent regional cerebral blood flow during $1-\mathrm{Hz}$ repetitive transcranial magnetic stimulation (rTMS) in healthy volunteers studied with $\mathrm{H} 215 \mathrm{O}$ positron emission tomography. II. Effects of prefrontal cortex rTMS. Biol Psychiatry 2003;54:826-832.

-41 Kimbrell TA, Dunn RT, George MS, Danielson AL, Willis MW, Repella JD, Benson BE, Herscovitch P, Post RM, Wassermann EM: Left prefrontal-repetitive transcranial magnetic stimulation (rTMS) and regional cerebral glucose metabolism in normal volunteers. Psychiatry Res 2002;115:101-113.

42 Shulman RG: Functional imaging studies: linking mind and basic neuroscience. Am J Psychiatry 2001;158:11-20.

43 Rocher AB, Chapon F, Blaizot X, Baron JC, Chavoix C: Resting-state brain glucose utilization as measured by PET is directly related to regional synaptophysin levels: a study in baboons. Neuroimage 2003;20:1894-1898.

-44 Engelien A, Stern E, Silbersweig D: Functional neuroimaging of human central auditory processing in normal subjects and patientswithneurologicaland neuropsychiatric disorders. J Clin Exp Neuropsychol 2001;23: 94-120.

45 Saleem KS, Suzuki W, Tanaka K, Hashikawa $\mathrm{T}$ : Connections between anterior inferotemporal cortex and superior temporal sulcus regions in the macaque monkey. J Neurosci 2000;20:5083-5101.

46 Seki M, Zyo K: Relationship between the hippocampal formation and the cortical and subcortical regions. Kaibogaku Zasshi 1992; 67:583-594.

47 Irle E, Markowitsch HJ: Connections of the hippocampal formation, mamillary bodies, anterior thalamus and cingulate cortex. A retrograde study using horseradish peroxidase in the cat. Exp Brain Res 1982;47:7994.

48 Middleton FA, Strick PL: Basal ganglia and cerebellar loops: motor and cognitive circuits. Brain Res Brain Res Rev 2000;31:236250 . 
49 Schmahmann JD, Pandya DN: Prefrontal cortex projections to the basilar pons in rhesus monkey: implications for the cerebellar contribution to higher function. Neurosci Lett 1995;199:175-178.

-50 Yurgelun-Todd DA, Waternaux CM, Cohen BM, Gruber SA, English CD, Renshaw PF: Functional magnetic resonance imaging of schizophrenic patients and comparison subjects during word production. Am J Psychiatry 1996;153:200-205.

-51 Gruzelier J, Liddiard D, Davis L, Wilson L: Topographical EEG differences between schizophrenic patients and controls during neuropsychological functional activation. Int J Psychophysiol 1990;8:275-282.

52 George MS, Stallings LE, Speer AM, Nahas Z, Spicer KM, Vincent DJ, Bohning DE, Cheng KT, Molloy M, Teneback CC, Risch SC: Prefrontal repetitive transcranial magnetic stimulation (rTMS) changes relative perfusion locally and remotely. Hum Psychopharmacol Clin Exp 1999;14:161-170.

$\checkmark 53$ Loo CK, Sachdev PS, Haindl W, Wen W, Mitchell PB, Croker VM, Malhi GS: High (15 $\mathrm{Hz})$ and low $(1 \mathrm{~Hz})$ frequency transcranial magnetic stimulation have different acute effects on regional cerebral blood flow in depressed patients. Psychol Med 2003;33:9971006.

54 Whittington MA, Traub RD, Kopell N, Ermentrout B, Buhl EH: Inhibition-based rhythms: experimental and mathematical observations on network dynamics. Int J Psychophysiol 2000;38:315-336.

-55 Oakes TR, Pizzagalli DA, Hendrick AM, Horras KA, Larson CL, Abercrombie HC, Schaefer SM, Koger JV, Davidson RJ: Functional coupling of simultaneous electrical and metabolic activity in the human brain. Hum Brain Mapp 2004;21:257-270.
56 Traub RD, Jefferys JG, Whittington MA: Simulation of gamma rhythms in networks of interneurons and pyramidal cells. J Comput Neurosci 1997;4:141-150.

-57 Sack AT, Camprodon JA, Pascual-Leone A, Goebel R: The dynamics of interhemispheric compensatory processes in mental imagery. Science 2005;308:702-704.

58 Porjesz B, Almasy L, Edenberg HJ, Wang K, Chorlian DB, Foroud T, Goate A, Rice JP, O'Connor SJ, Rohrbaugh J, Kuperman S, Bauer LO, Crowe RR, Schuckit MA, Hesselbrock V, Conneally PM, Tischfield JA, Li TK, Reich T, Begleiter $\mathrm{H}$ : Linkage disequilibrium between the beta frequency of the human EEG and a GABAA receptor gene locus. Proc Natl Acad Sci USA 2002;99:3729-3733.

59 Faulkner HJ, Traub RD, Whittington MA: Anaesthetic/amnesic agents disrupt beta frequency oscillations associated with potentiation of excitatory synaptic potentials in the rat hippocampal slice. Br J Pharmacol 1999; 128:1813-1825.

60 Altay EE, Fessler AJ, Gallagher M, Attarian HP, Dehdashti F, Vahle VJ, Ojemann J, Dowling JL, Gilliam FG: Correlation of severity of FDG-PET hypometabolism and interictal regional delta slowing in temporal lobe epilepsy. Epilepsia 2005;46:573-576.

61 Guich SM, Buchsbaum MS, Burgwald L, Wu J, Haier R, Asarnow R, Nuechterlein K, Potkin S: Effect of attention on frontal distribution of delta activity and cerebral metabolic rate in schizophrenia. Schizophr Res 1989;2: 439-448.
62 Molina V, Sanz J, Reig S, Martinez R, Sarramea $\mathrm{F}$, Luque $\mathrm{R}$, Benito C, Gispert JD, Pascau J, Desco M: Hypofrontality in men with first-episode psychosis. Br J Psychiatry 2005; 186:203-208

63 Davidson LL, Heinrichs RW: Quantification of frontal and temporal lobe brain-imaging findings in schizophrenia: a meta-analysis. Psychiatry Res 2003;122:69-87.

64 Paus T, Castro-Alamancos MA, Petrides M: Cortico-cortical connectivity of the human mid-dorsolateral frontal cortex and its modulation by repetitive transcranial magnetic stimulation. Eur J Neurosci 2001;14:14051411.

65 Pollock VE, Schneider LS, Lyness SA: Reliability of topographic quantitative EEG amplitude in healthy late-middle-aged and elderly subjects. Electroencephalogr Clin Neurophysiol 1991;79:20-26.

66 Salinsky MC, Oken BS, Morehead L: Test-retest reliability in EEG frequency analysis. Electroencephalogr Clin Neurophysiol 1991; 79:382-392.

67 van Beijsterveldt CE, Molenaar PC, de Geus EJ, Boomsma DI: Heritability of human brain functioning as assessed by electroencephalography. Am J Hum Genet 1996;58: 562-573.

68 Wassermann EM, Wedegaertner FR, Ziemann U, George MS, Chen R: Crossed reduction of human motor cortex excitability by $1-\mathrm{Hz}$ transcranial magnetic stimulation. Neurosci Lett 1998;250:141-144.

-69 Paus T, Jech R, Thompson CJ, Comeau R, Peters T, Evans AC: Dose-dependent reduction of cerebral blood flow during rapid-rate transcranial magnetic stimulation of the human sensorimotor cortex. J Neurophysiol 1998;79:1102-1107. 